\title{
Association of TCF7L2 rs7903146 Polymorphism with Diabetic Nephropathy in Type 2 Diabetes Mellitus Egyptian Patients
}

Abdelrahman Rabia Ali1, Alaa Mohamed Rabea1, Shimaa Ali Abdelkareem2, Rania Elsayed Sheirl. 1- Internal Medicine Department, Beni-Suef University; 2- Clinical and Chemical Department Beni-Suef University.

\begin{abstract}
:
Background: Transcription factor 7-like 2 (TCF7L2) gene polymorphisms are known risk factors for type 2 diabetes mellitus (T2DM). However, the relationship between TCF7L2 polymorphism and diabetic nephropathy (DN) is inconclusive. Objectives: to explore the association of TCF7L2 rs7903146 (C/T) gene polymorphism and DN in T2DM Egyptian patients. Methods: 80 patients with T2DM (40 patients without DN and 40 patients with DN) were enrolled in the study. Genotyping for the rs7903146 (C/T) polymorphism in TCF7L2 gene was performed by real time PCR.

Results: The frequency of rs7903146 genotypes in diabetic patients without DN was ( CC: $57.5 \%$; CT: 37.5\%; TT: 5\%), while in diabetic patients with DN was (CC: 2.5\%; CT: 40\%; TT: 57.5\%). Patients with DN were exposed to the TT 25.7 times more than who didn't develop DN (OR=25.7, $95 \% \mathrm{CI}=0.43-94, \mathrm{P}=0.001 * *)$. Upon examining the allelic discrimination, $\mathrm{C}$ allele was present in $77.5 \%$ of patients without DN versus $23.8 \%$ of patients with $\mathrm{DN}$, While $\mathrm{T}$ allele was found in $22.5 \%$ of patients without DN versus $76.3 \%$ of patients with DN. Patients with DN were exposed to the $\mathrm{T}$ allele 11 times more than who didn't develop nephropathy $(\mathrm{OR}=11,95 \% \mathrm{CI}=5.3-23.1$, $\mathrm{P}=<0.001 * *)$. Conclusion: rs7903146 TCF7L2 gene polymorphism may be significantly associated with the susceptibility to DN in Egyptian T2DM patients.
\end{abstract}

Keywords: Type 2 diabetes mellitus, diabetic nephropathy, TCF7L2 gene, rs7903146, polymorphism, Egypt. 


\section{Introduction:}

Diabetes mellitus (DM) is a major challenging worldwide health disease. The global diabe tes prevalence in 2019 is estimated to be $9.3 \%$ (463 million people), rising to $10.2 \%$ (578 million) by 2030 and $10.9 \%$ (700 million) by 2045 . The prevalence of DM is higher in urban $(10.8 \%)$ than rural $(7.2 \%)$ areas, and in highincome $(10.4 \%)$ than low-income countries (4.0\%)[1]. Type2DM (T2DM) seems to result from a complicated interplay of genetic and environmental factors influencing a number of intermediate traits of relevance to the diabetic phenotype (e.g., insulin secretion, insulin action, fat distribution, obesity)[2].

Over the past 2 decades there has been great progress in our understanding of the genetics of both type 1 diabetes and type 2 diabetes. This has been driven principally by genome-wide association studies (GWAS) which started to emerge in the literature around 2005, and such efforts have progressively advanced the field of diabetes genetics. Prior to GWAS, only a small number of loci were established for type 1 and type 2 diabetes [3]. GWAS have now revealed $>240$ loci for type 2 diabetes, corresponding to $>400$ independent association signals [4]. The Transcription factor 7-like 2 (TCF7L2) locus was the strongest and most statistically significant GWAS association signal in type 2 diabetes [5].

TCF7L2 gene also known as T-cell factor 4 (TCF4), is a member of TCF/lymphoid- enhancing factor family. TCF7L2 spans a 215,863 bases and is located on chromosome $10 q 25.3$ [6]. It encodes a transcription factor with a high-mobility box. TCF7L2 serves as a nuclear receptor for $\beta$-catenin, and functions in gene activations related to downstream events of the $\mathrm{Wnt} / \beta$-catenin pathway [7]. Selective disruption of TCF7L2 in the pancreatic $\beta$ cell impairs secretory function and lowers $\beta$ cell mass [8]. One of the genes transcriptionally regulated by $\mathrm{Wnt} / \beta$-catenin pathway is proglucagon, which encodes the insulinotropic hormone glucagon-like peptide 1 (GLP-1) [9].

It has been postulated that TCF7L2 gene variants may affect the susceptibility to T2DM by indirectly altering GLP-1 levels [10]. TCF7L2 is also involved in vascular remodeling through the regulation of smooth muscle cell proliferation and endothelial cell growth [11]. rs7903146 variant is one of the commonest single nucleotide polymorphisms (SNPs) that are connected to T2DM risk in different ethnic groups.

Diabetic nephropathy (DN) is a major microvascular complication developing in patients suffering from diabetes mellitus type 1 or 2, defined as albuminuria, worsening of glomerular filtration and arterial hypertension. Currently, approximately $40 \%$ of patients with diabetes develop kidney disease, making it the most prevalent cause of end-stage renal disease (ESRD)worldwide[12]. The prevalence 
of DN has grown recently due to growing global prevalence of type 2 diabetes [13]. The pathogenesis of DN is very complicated and many different cells, molecules, metabolic and molecular factors are involved in this process [14]. Metabolic factors, such as hyperglycemia and subsequent advanced glycation end (AGE) production, oxidative stress, and the activation of several signaling pathways are thought to be the driving force in the injury of renal cells and of extracellular matrix overproduction in DN [15].

Despite extensive studies, the prognosis of patients with DN is still hard to predict owing to differences in disease progression and a lack of effective prognostic parameters. In addition, current treatments, including renin-angiotensin system blockade as well as strict glycemic, lipid, and blood pressure control, are very limited, and none of these approaches can completely prevent the progression to end stage renal disease (ESRD). Therefore, it is essential to explore the molecular mechanisms of DN in order to establish accurate diagnostic tools and treatment modality regimens [16]. The current study aim was to investigate the effect of the rs7903146 polymorphisms of the TCF7L2 gene as a risk factor for development of DN in T2DM Egyptian patients.

\section{Materials and Methods:}

2.1. Patients: This case-control study was conducted on 80 patients with T2D of more than 10 years diabetes duration. The patients were recruited from the Diabetes Outpatient Clinic at Beni-Suef University Hospitals in upper Egypt during the period from April to October 2019.

This study was approved by the local research ethical committee in Beni-Suef university Hospital. The procedures followed were in accordance with the ethical standards of the responsible committee on human experimentation (Faculty of Medicine, Beni-Suef University) and with the Helsinki Declaration of 1975 , as revised in 1983. All participants provided informed consent to participate in this study.

Inclusion of the patients was based on the diagnosis of T2D according to the 2003 American Diabetes Association diagnostic criteria [17], and all the patients were on oral hypoglycaemic drugs.

Patients with type 1 diabetes mellitus, secondary diabetes mellitus due to other endocrinal diseases that affect glucose metabolism ,chronic pancreatitis, pregnancy, females with polycystic ovary syndrome (PCOS) and patients on hormonal treatment or drugs like (corticosteroids, beta- blockers and thiazide diuretics) were excluded from the study. 
Patients were further subclassified into 2 groups according to the urinary albumin/Creatinine ratio into: 40 patients without DN who had normoalbuminurea $(<30 \mu \mathrm{g} / \mathrm{mg}$ creatinine) and 40 patients with DN who had micro-albuminuria or macro-albuminuria $(>30$ $\mu \mathrm{g} / \mathrm{mg}$ creatinine).

All the patients were subjected to thorough history taking and proper clinical examination. Biochemical analysis was done for the measurement of haemoglobin (HB) level, so$\operatorname{dium}(\mathrm{Na})$, potassium $(\mathrm{K})$, fasting blood glucose (FBG) level, haemoglobin A1c (HbA1c), serum urea, serum creatinine and urinary albumin/creatinine ratio.

\subsection{TCF7L2 Genotyping Genotyping of} TCF7L2 gene polymorphism, rs7903146 was determined using real-time PCR allelic discrimination assays using Taq-Man_ SNP Genotyping Assays(Applied Bio systems Inc)*. Reactions were carried out according to the Manufacture's protocol.

The assay was done in the following steps: I- DNA extraction: DNA extraction was done from EDTA anti-coagulated whole blood using QIAamp DNA Mini Kit. *

II-Amplification of the target genes by (RTPCR): The region of of TCF7L2rs7903146 encompassing the SNP was amplified using TaqMan® 5- nuclease chemistry for amplifying and detecting specific polymorphisms in purified genomic DNA samples.
The TaqMan ${ }^{\circledR}$ MGB probes/extension primers were (VIC TAGAGAGCTAAGCACTTTTTAGATA ) to detect allele 1 sequence and (FAM TATATAATTTAATTGCCGTATGAGG ) to detect allele 2 sequence.

The successive cycles of DNA synthesis result in an exponential amplification of the target DNA sequence leading to a 105 to106 folds increase in the amount of DNA sequence of interest [18]. The total PCR reaction volume was $20 \mu \mathrm{L}$ : 40ng/ul gDNA, $10 \mu \mathrm{L} 2 \mathrm{x}$ universal TaqMan master mix II *, $0.5 \mu \mathrm{L} 20 x$ SNP assay mix and adjusted to a final volume of $20 \mu \mathrm{L}$ using nuclease free water.

The PCR was performed by Step-one real time PCR applied biosystem; under the following conditions: initial enzyme activation at 95 o $\mathrm{C}$ for $10 \mathrm{~min}$, followed by 40 cycles of amplification; denaturation at $950 \mathrm{C}$ for 15 secs, annealing / extension for $1 \mathrm{~min}$. at $60 \mathrm{o} \mathrm{C}$. Florescence data collection at annealing / extension step for 6 FAM and VIC dye.

III- Post - PCR plate read and analysis: Interpretation of data was done using allelic discrimination plot.

Life Technologies real-time instrument software plots the results of the allelic discrimination data as a scatter plot of Allele 1(VIC® dye) Versus Allele 2 (FAM day). 


\subsection{Statistical analysis:}

Analysis of data was performed using SPSS v. 25 (Statistical Package for Social science) for Windows.

Description of variables was presented as follows: Description of quantitative variables was in the form of mean, standard deviation (SD), median and range (min-max). Description of qualitative variables was in the form of numbers (No.) and percent's (\%). Chi square was used to detect the difference between both groups regarding categorical variables. One way ANOVA was used to detect the difference between groups regarding the scale variables. The significance of the results was assessed in the form of P-value that was differentiated into:Non-significant when P-value $>0.05$, Significant when P-value $\leq 0.05$ and Highly significant when P-value $\leq 0.001$.

\section{3-Results:}

General characteristics of study groups The mean age of DM patients without DM was ( $53.5 \pm 7.3$ ) years, and in patients with DN was ( $55.8 \pm 7.6)$ years. The age and sex of the 2 patients studied groups were matched with no statistically significant difference.

Different clinical and la boratory characteristics of both groups are shown in table (1).

Table (1) clinical and laboratory date of the two studied groups

\begin{tabular}{|c|c|c|c|}
\hline \multirow[t]{2}{*}{ Characteristics } & \multicolumn{2}{|c|}{ Groups } & \multirow[t]{2}{*}{ P-value } \\
\hline & $\operatorname{DM}(40)$ & DN(40) & \\
\hline $\mathrm{Hb}(\mathrm{gm} / \mathrm{dl}) * *$ & $11.2 \pm 1.2$ & $9.6 \pm 1.7$ & $<0.001 *$ \\
\hline $\operatorname{HbA1C}(\%)^{* * *}$ & $7.7 \pm 1.8$ & $7.5 \pm 0.9$ & 0.912 \\
\hline $\mathbf{N a}(\mathbf{m E q} / \mathbf{L})^{* * *}$ & $136.6 \pm 1.9$ & $136.6 \pm 5.4$ & 0.999 \\
\hline $\mathbf{K}(\mathbf{m E q} / \mathbf{L}) * *$ & $3.9 \pm 0.3$ & $4.6 \pm 0.84$ & $<0.001 *$ \\
\hline Urea $(\mathrm{mg} / \mathrm{dl})^{* *}$ & $27.4 \pm 2.3$ & $112.9 \pm 64.7$ & $<0.001 *$ \\
\hline $\begin{array}{l}\text { Creatinine } \\
(\mathrm{mg} / \mathrm{dl})^{* *}\end{array}$ & $0.95 \pm 0.1$ & $4.6 \pm 3$ & $<0.001 *$ \\
\hline
\end{tabular}




\begin{tabular}{|l|l|l|l|}
\hline A/C ratio*** & $\mathbf{2 4 . 5}(18-30)$ & $737.5(33-6900)$ & $<0.001 *$ \\
\hline
\end{tabular}

DM: type 2 diabetes without diabetic nephropathy, DN: type 2 diabetes with diabetic nephropathy, HbA1C:haemoglobinA1C, A/Cratio:albumin creatinine ratio, **mean $\pm S D$ and $* * *(I Q R)$, *P value $<0.05$ is considered significant

Genotyping and allele distribution of TCF7L2 rs7903146 SNPs in the two studied groups are demonstrated in table (2).

Table (2) Genotype and Allele frequency of TCF7L2 rs7903146 in the two studied groups

\begin{tabular}{|l|l|l|l|l|l|}
\hline \multirow{2}{*}{ TCF } & \multicolumn{2}{|l|}{ Groups } & P-value & $X^{2}$ & OR (95\% CI) \\
\cline { 1 - 3 } 7L2 & DM(40) & DN(40) & & & \\
\hline CC & $23(57.5 \%)$ & $1(2.5 \%)$ & $<0.001 * *$ & 29.2 & Reference category \\
\hline CT & $15(37.5 \%)$ & $16(40 \%)$ & 0.819 & 0.053 & $1.1(0.5-2.7)$ \\
\hline TT & $2(5 \%)$ & $23(57.5 \%)$ & $<0.001 * *$ & 28.94 & $25.7(0.43-94)$ \\
& & & & 4 & \\
\hline
\end{tabular}

DM:type 2 diabetes without diabetic nephropathy,DN: type 2 diabetes with diabetic nephropathy,

Values are $n(\%)$. **P value $<0.05$ is considered significant, $95 \%$ CI=95\% confidence interval, OR=odds ratio

Upon examining the allelic discrimina-

The frequency of rs7903146 genotypes in diabetic patients without DN was ( CC: $57.5 \%$; CT: 37.5\%; TT: 5\%), while in diabetic patients with DN was (CC: $2.5 \%$; CT: 40\%; TT: $57.5 \%)$. Patients with DN were exposed to the TT 25.7 times more than who didn't develop $\mathrm{DN}(\mathrm{OR}=25.7,95 \% \quad \mathrm{CI}=0.43-94, \quad \mathrm{P}=$ $0.001 * *)$. tion, $\mathrm{C}$ allele was present in $77.5 \%$ of patients without DN versus $23.8 \%$ of patients with DN, While $\mathrm{T}$ allele was found in $22.5 \%$ of patients without DN versus $76.3 \%$ of patients with DN. Patients with DN were exposed to the $\mathrm{T}$ allele 11 times more than who didn't develop nephropathy $(\mathrm{OR}=11,95 \% \mathrm{CI}=5.3$ 23.1, $\mathrm{P}=<0.001 * *)$. 
Comparing laboratory parameters with detected TCF7L2 rs7903146 genotypes in DN patients, no statistically significant difference could be detected between the 3 genotypes as displayed in table (3).

Table (3) The correlation between TCF7L2 genotype and the laboratory parameters in patients with diabetic nephropathy group:

\begin{tabular}{|c|c|c|c|c|c|}
\hline \multicolumn{2}{|l|}{ DN } & \multirow{2}{*}{$\begin{array}{l}\mathbf{N} \\
\mathbf{1}\end{array}$} & \multirow{2}{*}{$\begin{array}{l}\text { Mean } \\
7.400\end{array}$} & \multirow[t]{2}{*}{ Std. Deviation } & \multirow{2}{*}{$\begin{array}{l}\text { P-value } \\
0.368\end{array}$} \\
\hline $\mathrm{Hb}(\mathrm{gm} / \mathrm{dl})$ & $\mathrm{CC}$ & & & & \\
\hline & CT & 16 & 9.825 & 1.4126 & \\
\hline & TT & 23 & 9.452 & 1.8964 & \\
\hline \multirow[t]{3}{*}{ NA (mEq/L) } & $\mathrm{CC}$ & 1 & 135.00 & - & \multirow[t]{3}{*}{0.196} \\
\hline & CT & 16 & 138.50 & 4.115 & \\
\hline & TT & 23 & 135.35 & 6.005 & \\
\hline \multirow[t]{3}{*}{$\mathbf{K}(\mathbf{m E q} / \mathbf{L})$} & $\mathrm{CC}$ & 1 & 3.800 & - & \multirow[t]{3}{*}{0.640} \\
\hline & CT & 16 & 4.625 & .6817 & \\
\hline & TT & 23 & 4.617 & .9514 & \\
\hline \multirow{3}{*}{$\begin{array}{l}\text { UREA(mg/d } \\
\text { l) }\end{array}$} & $\mathbf{C C}$ & 1 & 103.00 & - & \multirow[t]{3}{*}{0.818} \\
\hline & CT & 16 & 121.06 & 63.619 & \\
\hline & TT & 23 & 107.77 & 67.743 & \\
\hline \multirow{3}{*}{$\begin{array}{l}\text { Creatinine } \\
(\mathrm{mg} / \mathrm{dl})\end{array}$} & $\mathrm{CC}$ & 1 & 7.700 & - & \multirow[t]{3}{*}{0.583} \\
\hline & CT & 16 & 4.400 & 2.8612 & \\
\hline & TT & 23 & 4.617 & 3.1863 & \\
\hline \multirow[t]{3}{*}{ HbA1C (\%) } & $\mathrm{CC}$ & 1 & 7.200 & - & \multirow[t]{3}{*}{0.520} \\
\hline & CT & 16 & 7.340 & 1.4777 & \\
\hline & TT & 23 & 8.017 & 2.0841 & \\
\hline \multirow[t]{3}{*}{ A/C Ratio } & $\mathrm{CC}$ & 1 & 225.00 & • & \multirow[t]{3}{*}{0.639} \\
\hline & CT & 16 & 1158.38 & 1242.480 & \\
\hline & TT & 23 & 1473.13 & 1717.174 & \\
\hline
\end{tabular}


DN: type 2 diabetes with diabetic nephropathy, HbAlC:haemoglobinAlC, A/C ratio:albumin creatinine ratio, $N$ :number

\section{Discussion:}

$\mathrm{DN}$ is a chronic kidney disease and is a major microvascular complication of diabetes mellitus. The pathogenesis of $\mathrm{DN}$ is very compli cated and many different cells, molecules, and multifactors are involved in this process [19].

However, the pathogenesis of DN is still unclear. It has been known since 2006 that Transcription factor 7-like 2 (TCF7L2) gene is strongly associated with occurrence of T2DM and that its relative strength is higher than most other GWAS-implicated common loci reported to date [3].

Accumulating studies have shown that Wnt/ $\beta$-catenin signaling, a multifunctional pathway, is involved in renal cell injury, including mesangial cells, podocytes, and tubular cell damage as well as in tubular interstitial fibrosis in DN [20]. Wnt/ $\beta$-catenin signaling pathway can cross talk with transforming growth factor- $\beta$ (TGF- $\beta$ )/Smad, Notch pathways and connective tissue growth factor (CTGF). These interactions play a pivotal role in embryonic proliferation, differentiation, cell adhesion, cell survival and apoptosis and is involved in organ development and diseases, including various kidney diseases, particularly diabetic nephropathy [21].

TCF7L2 has attracted intense interest in the exploration and elucidation of the effect of $\mathrm{Wnt} / \beta$-catenin signaling in DN progression. However, the relationship between TCF7L2 polymorphism and DN is still inconclusive.

The first study to examine TCF7L2 rs7903146 correlation with T2DM in Egyptians was done on 2016. They showed that TCF7L2 rs7903146 polymorphism was associated with T2DM. rs7903146 variant T allele was associated with 1.6-fold increased risk for T2DM and TT genotype carriers were at 2.3folds higher risk than wild genotype (CC) carriers [22]. On the contrary, subsequent study was done by Mandour et al.,2018 showed that T allele of TCF7L2 rs7903146 was associated with lower risk of T2DM in Egyptian population, and that TT genotype frequency was higher in healthy subjects [23]. Based on this knowledge, this study was designed to assess TCF7L2 rs7903146 gene polymorphism in a group of T2DM patients with and without DN in order to emphasize its possible role as a risk factor and an early predictor of susceptibility to $\mathrm{DN}$ in Egyptian population.

Our results showed that there was an association between TCF7L2 rs7903146 polymorphism and DN patients. TT genotype frequency was significantly higher in diabetic patients with DN than those without DN (57.5\% versus $5 \%$ respectively). $\mathrm{T}$ allele was found in $76.3 \%$ of patients with DN versus $22.5 \%$ of patients without DN. Patients with 
$\mathrm{DN}$ were exposed to the $\mathrm{T}$ allele 11 times more than who didn't develop nephropathy $(\mathrm{OR}=11,95 \% \mathrm{CI}=5.3-23.1, \mathrm{P}=<0.001 * *)$, suggesting that $\mathrm{T}$ allele has a role as a risk allele for DN occurrence.

These results were in agreement with the study conducted by Zhuang et al., on Chinese Han population [23]. They found that patients carrying TT genotype of rs7903146 were more easily to be attacked by DN than CC genotype carriers $(\mathrm{P}=.02, \mathrm{OR}=4.26,95 \%$ $\mathrm{CI}=1.12-16.24)$. Meanwhile, $\mathrm{T}$ allele also showed 1.85 times risk to suffer from DN compared with $\mathrm{C}$ allele $(\mathrm{OR}=1.85,95 \%$ $\mathrm{CI}=1.02-3.10)$. They concluded that TCF7L2 rs7903146 polymorphism may be associated with the susceptibility to DN in Chinese Han population. Additionally, T haplotype is also a risk factor for DN.

A meta analysis result provided a new evidence that TCF7L2 rs7903146 gene polymorphism was associated with DN risk. In the subgroup analysis by ethnicities, the result indicated that TCF7L2 gene polymorphism was associated with DN risk in Asian and Caucasian, but not in Negroid [25]. They presumed that the limited studies and sample size of subject might be the reason on this inconsistency.

Another study from south India demonstrated that the ' $\mathrm{T}$ ' allele is associated with both diabetes $(\mathrm{p}=0.049)$ and $\mathrm{DN}(\mathrm{p}=$ $0.024)$, but this association is not independent of T2DM [26]. In accordance with our study an association was observed in Caucasian population between rs7903146 and
$\mathrm{DN}(\mathrm{p}<0.001)$, with $22 \%$ of TT homozygotes in this subgroup vs. $11 \%$ in patients without $\mathrm{DN}(\mathrm{p}=0.006$, OR for TT $2.83,95 \%$ CI 1.94 4.13). Association was stronger in patients with early onset of diabetes (34\% of TT vs. $12 \%$ in the late onset, $\mathrm{p}<0.001)$. In $\mathrm{DN}$ group $71 \%$ of TT homozygotes had an early onset (OR 7.64, 95\% CI 4.98-11.73 vs. controls) [27]. Furthermore, recent study showed that the frequency of the $\mathrm{T}$ allele was significantly higher in patients with diabetic nephropathy versus non-diabetic renal disease $(\mathrm{p}=0.007$, OR 1.70, 95\% CI 1.36-2.11) [28].

This finding may be a reflection of the interplay between genetic and metabolic factors in T2DM. The Wnt/ $\beta$-catenin signaling pathway has been shown to be activated under DN conditions, which was involved in the apoptosis and epithelial mesenchymal transition (EMT) formation of mesangial cells, podocyte dysfunction, and tubular cells EMT, subsequently resulting in renal fibrosis and interstitial fibrosis. Sustained Wnt/ $\beta$-catenin expression is essential for its protective role against cellular damage, as TCF7L2 was recently found to protect pancreatic cells against interleukin-1 and interferon induced cell apoptosis, stimulates cell proliferation and mediates glucose stimulated insulin secretion [29], while abnormal activation of $\mathrm{Wnt} / \beta$-catenin results in adverse effects and promotes the progression of DN [30].

The specific purpose of $\mathrm{Wu}$ et al., work was to investigate the gene-gene interactions in the hypothesis that small single-gene 
effects could not be detected by single-locus studies. In their study, the TCF7L2 gene was not associated with DN in T2DM (in either genotypic test or odds ratio analysis) using single-locus analyses. However, by the generalized multifactor dimensionality reduction (GMDR) analyses, they further established interaction models among TCF7L2 and other candidate genes. This may be explained by that the TCF7L2 gene may contribute to the pathogenesis of DN in T2DM in an interactive manner with other genes [31].

A study conducted by Köttgen et al., 2008. demonstrated association of TCF7L2 rs7903146 $\mathrm{T}$ allele with chronic kidney disease (CKD) progression in individuals with diabetes as well as in individuals without known diabetes [32].

This happens not only through their effect on diabetes but also possibly through other renal-specific mechanisms such as pleiotropic effect.

There is strong belief that novel type 2 diabetes genes offer new promising therapeutic opportunities, as has been seen previously with the peroxisomal proliferator-activated receptor $\gamma$ (PPARG) gene with thiazolidinediones therapy [33], and with the KCNJ11 gene (encoding Kir6.2) in relation to sulfonylurea treatment [34]. Whether TCF7L2 gene could be a promising target gene for early prediction or as a treatment modality for DN needs further research and intense work on larger groups of patients.

\section{5- Conclusion:}

The present study showed that there was a significant association between TCF7L2 rs7903146 polymorphism and the risk of developing DN in Egyptian patients. TT genotype and $\mathrm{T}$ allele were associated with higher risk of developing DN.

Some limitations are found in our study. Firstly, the sample size was small to obtain enough results. Secondly, no healthy control group were included to verify whether the association of TCF7L2 with DN is directly related to renal affection or dependent on the occurrence of DM. Lastly, interactions with other implicated factors affecting kidney functions such as hypertension, glycemic control, smoking, obesity and others were not considered in this study.

\section{Ethics Approval And Consent To Partici-} pate:

This study was approved by the local research ethical committee in Beni-Suef University hospital, Egypt.

\section{Human And Animal Rights:}

All procedures followed were in accordance with the ethical standards of the responsible committee on human experimentation (institutional and national) and with the Helsinki Declaration of 1975, as revised in 2008.

\section{Consent For Publication:}

Informed consent was obtained from all patients for be- ing included in the study.

\section{Availability Of Data And Materials:}


The data used to support the findings of this study are in- cluded within the supplementary information file.

\section{Funding:}

None.

\section{Conflict Of Interest:}

The authors declare no conflict of interest, financial or otherwise.

\section{Acknowledgment:}

The authors would like to thank members of internal medicine department and clinical laboratory in Bani-Suef hospital university.

\section{6- References:}

1. Saeedi P, Petersohn I, Salpea P, Malanda B, Karuranga S, Unwin N, Colagiuri S, Guariguata L, Motala AA, Ogurtsova K, Shaw JE, Bright D, Williams R; IDF Diabetes Atlas Committee. Global and regional diabetes prevalence estimates for 2019 and projections for 2030 and 2045: Results from the International Diabetes Federation Diabetes Atlas, 9th edition. Diabetes Res Clin Pract. 2019 Nov;157:107843.

2. Tong Y1, Lin $\mathrm{Y}$, Zhang Y, Yang J, Zhang Y, Liu H, Zhang B . Association between TCF7L2 gene polymorphisms and susceptibility to type 2 diabetes mellitus: a large Human Genome Epidemiology (HuGE) review and meta-analysis. Review article. BMC Med Genet. 2009 Feb 19;10:15.

3. Grant SFA. The TCF7L2 Locus: A Genetic Window Into the Pathogenesis of Type 1 and Type 2 Diabetes. Diabetes Care. 2019 Sep;42(9):1624-1629.
4. Mahajan A, Taliun D, Thurner M, et al. Fine-mapping type 2 diabetes loci to single-variant resolution using high-density imputation and islet-specific epigenome maps. Nat Genet 2018;50:1505-1513.

5. Sladek R, Rocheleau G, Rung J, et al. A genome-wide association study identifies novel risk loci for type 2 diabetes. Nature 2007;445:881-885.

6. Duval A, Busson LM, Berger R. Assignment of the TCF-4 gene (TCF7L2) to human chromosome band 10q25.3. Cytogenet Cell Genet 2000; 88:264-265.

7. Grant SF, Thorleifsson G, Reynisdottir I, et al. Variant of transcription 7-like 2 (TCF7L2) gene confers risk of type 2 diabetes. Nat Genet 2006; 38:320-323.

8. Mitchell RK, Mondragon A, Chen L, et al. Selective disruption of Tcf712 in the pancreatic $\beta$ cell impairs secretory function and lowers $\beta$ cell mass. Hum Mol Genet 2015; 24:1390-1399.

9. Prunier C, Hocevar BA, Howe PH. Wnt signaling: physiology and pathology. Growth Factors. 2004;22:141-150.

10. Yi F, Brubaker PL, Jin T. TCF-4 mediates cell type-specific regulation of proglucagon gene expression by beta-catenin and glycogen synthase kinase-3beta. J Biol Chem. 2005;280:1457-1464.

11. Wang X, Xiao Y, Mou Y, et al. A role for the beta-catenin/T-cell factor signaling cascade in vascular remodeling. Circ Res 2002;90:340-7. 
12. Lavoz C, Rayego-Mateos S, Orejudo M, Opazo-Ríos L, et al. Could IL-17A Be a Novel Therapeutic Target in Diabetic Nephropathy? Review article. J Clin Med. 2020 Jan 19;9(1).

13. Podgórski P, Konieczny A, Lis Ł, Witkiewicz W, Hruby Z. Glomerular podocytes in diabetic renal disease. Adv Clin Exp Med. 2019 Dec;28(12):1711-1715.

14. Sun YM, Su Y, Li J, Wang LF. Recent advances in understanding the biochemical and molecular mechanism of diabetic nephropathy. Biochemical and Biophysical Research Communications. 2013;433:359361.

15. Brosius FC, III, Khoury CC, Buller CL, Chen S. Abnormalities in signaling pathways in diabetic nephropathy. Expert Review of Endocrinology and Metabolism. 2010;5(1):51-64.

16. Tang YL, Dong XY, Zeng ZG, Feng Z. Gene expression-based analysis identified NTNG1 and HGF as biomarkers for diabetic kidney disease. Medicine (Baltimore). 2020 Jan;99(1):e18596.

17. Genuth S, Alberti KG, Bennett P, et al. Follow-up report on the diagnosis of diabetes mellitus. Diabetes Care 2003; 26(11): 3160-7.

18. Pavlov V1, Xiao Y, Gill R, Dishon A, Kotler M, Willner I. Amplified chemiluminescence surface detection of DNA and telomerase activity using catalytic nucleic acid labels. Anal Chem. 2004 Apr 1;76(7):2152-6.
19. Sun YM, Su Y, Li J, Wang LF. Recent advances in understanding the biochemical and molecular mechanism of diabetic nephropathy. Biochemical and Biophysical Research Communications. 2013;433:359361.

20. Wang Y, Li H, Song SP. $\beta$-Arrestin $1 / 2$ Aggravates Podocyte Apoptosis of Diabetic Nephropathy via Wnt/ $\beta$-Catenin Pathway. Med Sci Monit. 2018 Mar 24;24:17241732.

21. He W, Dai C, Li Y, Zeng G, Monga SP, Liu Y. Wnt/ $\beta$-catenin signaling promotes renal interstitial fibrosis. Journal of the American Society of Nephrology. 2009;20(4):765-776.

22. El-Lebedy D, Ashmawy I. Common variants in TCF7L2 and CDKAL1 genes and risk of type 2 diabetes mellitus in Egyptians. J Genet Eng Biotechnol. 2016 Dec;14(2):247-251.

23. Mandour I, Darwish R, Fayez R, Naguib M, El-Sayegh S. TCF7L2 Gene Polymorphisms and Susceptibility to Type 2 Diabetes Mellitus, A Pilot Study. Biomed Pharmacol J 2018; 11(2): 1043-9.

24. Zhuang Y, Niu F, Liu D, Sun J, Zhang X, Zhang J, Guo S. Associations of TCF7L2 gene polymorphisms with the risk of diabetic nephropathy: A case-control study. Medicine $\quad 2018$ Oct;97(40):e8388.

25. Fan Z, Cai Q, Chen Y, et al. Association of the Transcription Fac- tor 7 Like 2 (TCF7L2) Polymorphism With Diabetic 
Nephropathy Risk: A Meta-Analysis. Medicine (Baltimore). 2016; 95(11)e3087.

26. Hussain H, Ramachandran V, Ravi S, et al. TCF7L2 rs7903146 polymorphism and diabetic nephropathy association is not independent of type 2 diabetes - a study in a south Indian population and meta-analysis. Endokrynol Polska 2014;65:298-305.

27. Buraczynska M, Swatowski A, Markowska-Gosik D, et al. Transcription factor 7like 2 (TCF7L2) gene polymorphism and complication/comorbidity profile in type 2 diabetes patients. Diabet Res Clin Pract 2011;93:390-5.

28. Buraczynska M, Zukowski P, Ksiazek P, et al. Transcription factor 7-like 2 (TCF7L2) gene polymorphism and clinical phenotype in end-stage renal disease patients. Mol Biol Rep 2014;41:4063-8.

29. Jin T. Current understanding on role of the Wnt signaling pathway effector TCF7L2 in glucose homeostasis. Endocrine reviews 2016; 37: 254-277.

30. Xiao L, Wang M, Yang S, Liu F, Sun L. A glimpse of the pathogenetic mechanisms of Wnt/ $\beta$-catenin signaling in diabetic nephropathy. Biomed Res Int. 2013;2013:987064.

31. Wu LS, Hsieh CH, Pei D, Hung YJ, Kuo SW, Lin E. Association and interaction analyses of genetic variants in ADIPOQ, ENPP1, GHSR, PPARgamma and TCF7L2 genes for diabetic nephropathy in a Taiwanese population with type 2 diabetes. Nephrol Dial Transplant. 2009 Nov;24(11):3360-6.

32. Köttgen A, Hwang S-J, Rampersaud E, et al. TCF7L2 variants associate with CKD progression and renal function in population- based cohorts. J Am Soc Nephrol. 2008; 19(10): 1989- 99.

33. Takada I, Makishima M. Peroxisome proliferator-activated receptor agonists and antagonists: a patent review (2014-present). Review article. Expert Opin Ther Pat. 2020 Jan;30(1):1-13.

34. Karaglani M, Ragia G, Panagopoulou M, Balgkouranidou I, Nena E, Kolios G, Papanas N, Manolopoulos VG, Chatzaki E. Search for Pharmacoepigenetic Correlations in Type 2 Diabetes Under Sulfonylurea Treatment. Exp Clin Endocrinol Diabetes. $2019 \quad$ Apr;127(4):226-233. 